September - 2020

\title{
Promoting Intercultural Competence in a Learning Activity Supported by Virtual Reality Technology
}

Rustam Shadiev ${ }^{1}$, Wang Xueying ${ }^{1}$, and Yueh Min Huang ${ }^{2}$,

${ }^{1}$ Nanjing Normal University, China, ${ }^{2}$ National Cheng Kung University, Taiwan

${ }^{*}$ Corresponding author

\begin{abstract}
Virtual reality (VR) technology makes it possible to create an authentic virtual environment that benefits immersive learning. We designed an intercultural learning activity and applied VR technology to support it. Then, we investigated students' perceptions of the learning activity, VR technology, and intercultural competence (IC) development during learning. Students from China and Uzbekistan participated in the activity, in which a pragmatic mixed-methods approach was used. The data were collected through student reports, three questionnaires, and interviews, and then analyzed. Three main findings were obtained. First, 13 items related to perception of the learning activity were revealed. When compared with earlier studies, new items were found, including presence, immersion, and authentic cultural experience. Second, the results showed that the participants intended to continue using VR technology, were satisfied with intercultural learning supported by VR technology, and felt that the technology confirmed their expectations. Third, the results showed that intercultural learning supported by VR technology helped facilitate IC development. Based on these results, we discuss implications and offer suggestions for educators and researchers.
\end{abstract}

Keywords: intercultural competence, learning activity, virtual reality, technology 


\section{Introduction}

Intercultural communication is defined as interaction between people of different cultures (Çiftçi, 2016). Intercultural learning aims to cultivate the ability of students to communicate effectively with people from different cultural backgrounds. To best develop students' intercultural abilities, the ideal choice would be to immerse them in another culture for a period of time and allow them to engage in face-toface communication with local people (Yang, 2018). However, for various reasons (e.g., time, expense, and recent travel restrictions due to the pandemic), few people have the chance to go abroad. The use of computer technology can break through the limitations of time and space and create an environment in which people from different cultural backgrounds can have immersive experiences (Avgousti, 2018; Çiftçi, 2016).

A significant amount of literature has been published on technology-supported intercultural learning. According to Avgousti (2018) and Çiftçi (2016), a number of technological tools have been used to support intercultural learning, including e-mail, blogs, Facebook, and Skype. However, none of these is able to create authentic contexts in which participants can experience a sense of presence and immersion. Emerging technology (e.g., a new technology or an existing technology under continuing development), such as virtual reality (VR), offers potential for making the intercultural learning environment more immersive and authentic, providing participants with a good sense of presence. However, to the best of our knowledge, few studies have been carried out using VR technology to support the communication of interlocutors from different cultures. Specifically, whether such a technological approach facilitates intercultural competence (IC) has not yet been tested. This study is an attempt to address the existing gaps in research. Informed by related studies on IC, VR, and expectation-confirmation theory, a theoretical framework was built, and a pragmatic mixed-methods approach was used for data collection and analysis.

\section{Literature Review}

\section{Online Intercultural Learning}

Culture is generally considered to consist of a set of knowledge, behaviours, attitudes, ideas, and traditions formed within a group of people and shared generation to generation (Shih, 2015). According to Shadiev and Sintawati (2020), intercultural learning is a process in which individuals acquire new knowledge and skills through experience and participation, as well as absorb new attitudes and values from different cultures. In our globalized society, people with different cultural backgrounds are becoming closer, and interaction between them is becoming common. In addition, understanding the culture of others helps maintain harmonious relationships. Although the best way to learn about another culture is to be in that environment, few people have this opportunity. The development of technology is providing the possibility of achieving distant intercultural learning, i.e., a kind of education in which the main elements include physical separation of the instructor and students during instruction (Shadiev \& Sintawati, 2020; Shadiev, Sun, \& Huang, 2019). Various technological tools can be used in distant intercultural learning to facilitate student-teacher and student-student communication, e.g., e-mail, blogs, Facebook, and Skype (Avgousti, 2018; Çiftçi, 2016). 
Online intercultural learning has received a significant amount of attention in the past few years (Avgousti, 2018; Çiftçi, 2016). For example, in the work of Bueno-Alastuey and Kleban (2016), participants from Spain and Poland engaged in a project to develop their English language and intercultural skills. They used Dropbox and e-mail to exchange recorded text and audio files, and Skype for synchronous communication. The results demonstrated that participants were satisfied and appreciated the opportunity to use the target language authentically. In addition, they valued the potential of the project for enhancing IC. Hsu and Beasley (2019) carried out a project in which students from the USA and Taiwan interacted with each other using e-mail and Skype. These scholars found that participants positively perceived their intercultural learning experiences: intercultural communication facilitated efficient online discussions between non-native and native speakers of the target language and promoted their IC. Yang (2018) introduced a questioning strategy to online intercultural communication among students from the USA and China. Students asked each other self-generated questions using instant chatting tools. The results showed that the questioning strategy was useful for cross-cultural understanding and language development.

In previous studies, participants used both synchronous and asynchronous online tools for communication. These tools enabled them to use the target language authentically and communicate with representatives of the target culture. However, participants were unable to get a sense of presence and immerse themselves. Emerging technology makes this possible by creating intercultural learning environments that are immersive, authentic, and lead to a good sense of presence.

\section{Assessing Intercultural Competence}

Byram (1997) and Deardorff (2006) are seminal authors on the concept of IC. They argue that the primary goal of any online intercultural learning program is to develop learners' IC. Deardorff (2006, p. 247) defined IC as the "ability to communicate effectively and appropriately in intercultural situations based on one's intercultural knowledge, skills, and attitudes." Fantini (2009) suggested that IC includes four components: knowledge, skill, attitude, and awareness. Byram (1997) defined these components as follows: knowledge is "knowledge of social groups and their products and practices in one's own and in one's interlocutor's country"; skill of interpreting/relating is "the ability to interpret a document or event from another culture, as well as to explain it and relate it to documents or events from one's own experiences"; skill of discovery and interaction is "the ability to acquire new knowledge of a culture and cultural practices and the ability to operate knowledge, attitudes, and skills under the constraints of real-time communication and interaction"; attitude is "curiosity and openness, readiness to suspend disbelief about other cultures and belief about one's own culture"; and, awareness is "the ability to evaluate critically on the basis of explicit criteria, perspectives, practices, and products in one's own and other cultures and countries."

According to Fantini (2009), IC can be measured by the Assessment of Intercultural Competence (AIC) instrument. Using only one set of data (e.g., questionnaires) makes it difficult to comprehensively measure IC development because the process is complex and may be influenced by many factors, such as the learners themselves or their partners and the learning environment. Therefore, different sets of data (e.g., interviews and student reflections) should be used to make findings robust. 


\section{0-Degree Video-Based VR Technology}

VR is a computer simulation environment in which users navigate and manipulate virtual objects in a virtual world. VR can simulate immersion and interaction in a target culture and language, and users can interact with the simulated environment through special wearable devices (Walshe \& Driver, 2019).

In recent years, VR based on 360-degree video has emerged. It comprises a VR multi-lens camera and image Mosaic technology, which combines video shots from multiple lenses into a spherical image to build a dynamic virtual space. The video viewing methods include direct displays and head-mounted displays (HMDs), both of which can be supported by mobile and PC terminals (Rupp et al., 2019). Compared to a direct display, using a HMD is a more immersive approach to learning. According to Rupp et al. (2019) and Walshe and Driver (2019), HMDs induce a greater sense of place illusion, have greater positive effects, and are more convenient compared to a direct display. Previous studies created VR based on 360-degree video and HMD (Rupp et al., 2019; Vettehen, Wiltink, Huiskamp, Schaap, \& Ketelaar, 2019; Walshe \& Driver, 2019), and their results showed that VR has strong potential as a learning technology. For example, Walshe and Driver (2019) applied a 360-degree video to help preservice teachers gain a nuanced understanding of microteaching practice, as well as to support their self-efficacy in teaching. Vettehen, Wiltink, Huiskamp, Schaap, and Ketelaar (2019) investigated the use of 360-degree video as a means for conveying news stories to determine what it might add to traditional two-dimensional video. The results showed that 360-degree video received a higher evaluation in terms of presence, enjoyment, and credibility, with no negative effects on recognition and understanding. Research has identified a number of desirable characteristics of 360-degree video including broad perspective, large information capacity, easily produced immersion, and strong interaction, and it can provide rich visual and auditory information, showing learners a very realistic, broad-space picture (Rupp et al., 2019). However, to the best of our knowledge, few studies have been carried out using this kind of technology for IC learning. Particularly, whether such a technological approach facilitates IC has not yet been tested. Therefore, this study is an attempt to address this gap.

\section{Expectation-Confirmation Theory}

Bhattacherjee (2001) is considered by many to be the seminal author on expectation-confirmation theory (ECT). According to Bhattacherjee (2001), ECT describes the relationship between consumer expectations before buying a product, the perceived effects after purchase, the degree of confirmation between expectations and effects, the degree of satisfaction after purchase, and the intention of buyers to buy again. Based on ECT, Bhattacherjee (2001) proposed the expectation-confirmation model to compare the behaviour of people using information systems with the purchase behaviour of consumers, positing there to be a high degree of consistency between the two. In addition, the type of experience on the first use of an information system will determine a person's intention to use the system either again or continuously. According to the expectation-confirmation model, users' perceptions of technology include the degree of satisfaction and confirmation of expectations, which in turn affect their continuance intentions. Studies on intercultural learning supported by technology have typically investigated participants' perceptions of the technology (Lee \& Markey, 2014; Shadiev, Hwang, \& Huang, 2015; Shadiev \& Sintawati, 2020). In a study reviewed by Çiftçi (2016), participants had a positive attitude and overall satisfaction with digital technologies and intercultural learning, and the technologies provided enjoyable intercultural experiences. Since many new technologies are emerging 
and can be applied to support intercultural learning, researchers should explore learners' perceived experiences (e.g., expectation-confirmation) with them.

\section{Research Questions}

This study was aimed toward addressing the following research questions:

1. What were participants' perceptions of the intercultural learning activity?

2. What were participants' perceptions of VR technology during the intercultural learning activity?

3. To what extent did the learning activity supported by VR technology promote intercultural competence?

\section{Method}

Our study used a pragmatic mixed-methods approach as a way of gaining a deeper understanding of the phenomenon of interest. This research method can be used to collect a substantial amount of evidence and information.

\section{Participants}

We used a convenience sampling method, i.e., participants were selected based on availability and willingness to take part. Twenty-one university students, ten from China and eleven from Uzbekistan, voluntarily participated in the learning activity. They were recruited by means of messages posted to online student groups in two universities and provided informed written consent. The students ranged in age from 20 to 25, and they were majoring in education science. The participants' English level was good enough for intercultural communication; all had passed a national college entrance examination, which included English as a foreign language. The participants had no experience with using the VR technology employed in this study, nor did they have any intercultural learning experience. To protect their privacy in this paper, each participant was assigned an identification number ranging from ID1 to ID21.

\section{Intercultural Learning Activity}

A three-step intercultural learning activity was designed for this study:

1. Self-introduction. The participants were asked to introduce themselves, their hobbies, and interests, as well as their daily life and their culture. Each student recorded his/her selfintroduction using a 360-degree camera and uploaded it to the activity website.

2. Introducing local culture. The participants were asked to choose a topic of interest from a list of predetermined options, to introduce it with relation to their local culture, to record their introductions using a 360-degree camera, and then to upload their recordings online. For example, student ID8 described a traditional breakfast and its history in relation to his/her culture. 
3. Experiencing foreign culture. In this step, each participant was asked to watch videos using Gear VR, to reflect on his/her personal experience of a foreign culture and tradition in a reflective report, and then to share it with other participants online. These videos had to be on the same topic introduced by the student. That is, if student ID8 introduced traditional food, he/she had to watch videos created by student ID17, who also introduced traditional food, and reflect on them.

Each step took one week. Videos were of different lengths, ranging between three and nine minutes. Communication among participants during the three steps was carried out in English on the activity website and took place asynchronously. The participants communicated in pairs (i.e., two students who selected the same topic of interest), and no instances of collaboration on each other's videos were observed. The participants received guidelines on how to communicate with their partners (e.g., communication content had to be appropriate and relevant to the topic), and there was not a required minimum number of responses.

The website used for the activity was created on the server in the research lab and included instructions for use of VR tools, the steps in the learning activity, and guidelines to complete them efficiently, as well as the videos created by the participants.

One may argue that the sample size of this study was small and that the learning activity was short. Our review of related studies showed that many also involved a small number of participants (e.g., four students in the research of Liao and Lu [2018], twelve students in Yang's work [2018], eighteen students in Bueno-Alastuey and Kleban [2016], and thirty-four students in Hsu and Beasley [2019]), and their projects were short (e.g., one week in the case of Liao and Lu [2018], five weeks for Bueno-Alastuey and Kleban [2016], and six weeks for Yang [2018]).

\section{0-Degree Video-Based VR Technology}

Two pieces of VR-related technology facilitated the learning experience: a 360-degree video recorder and an HMD to view the videos. Samsung Gear 360 was used to make the videos. It is a camera that can capture a full 360-degree view around a person in the form of a video using a smartphone. Samsung Gear VR was used to watch the 360-degree videos. It is a lightweight headset device powered by Oculus and is compatible with Samsung Galaxy flagship smartphones. We used Samsung Galaxy S9 plus mobile phones to connect to Samsung Gear 360 to record the 360-degree videos and to connect to the Samsung Gear VR to watch the 360-degree videos without transferring the videos to Gear VR. These tools were selected because of their availability and current use in the field.

We used 360-degree video-based VR technology instead of artificially simulated VR (e.g., Second Life) because people, objects, and scenarios in the former look the same as they do in real life, so we assumed that the degree of perceived authenticity and immersion of the participants would be higher as compared to the latter. In addition, it is difficult for non-professionals such as teachers to design artificially simulated VR; however, due to the ease of 360-degree cameras use, non-professionals can create their own 360-degree video-based VR.

Two screenshots from a 360-degree video are shown in Figure 1. The participant in the first screenshot 
demonstrates kelin ko'ylyagi, a traditional Uzbek dress for young brides, and the participant in the second screenshot explains zhongzhi, a traditional Chinese rice dish. Figure 2 demonstrates a participant watching a 360-degree video using Samsung Gear VR (1), and a participant (in the background) recording a 360-degree video using Samsung Gear 360 (2).

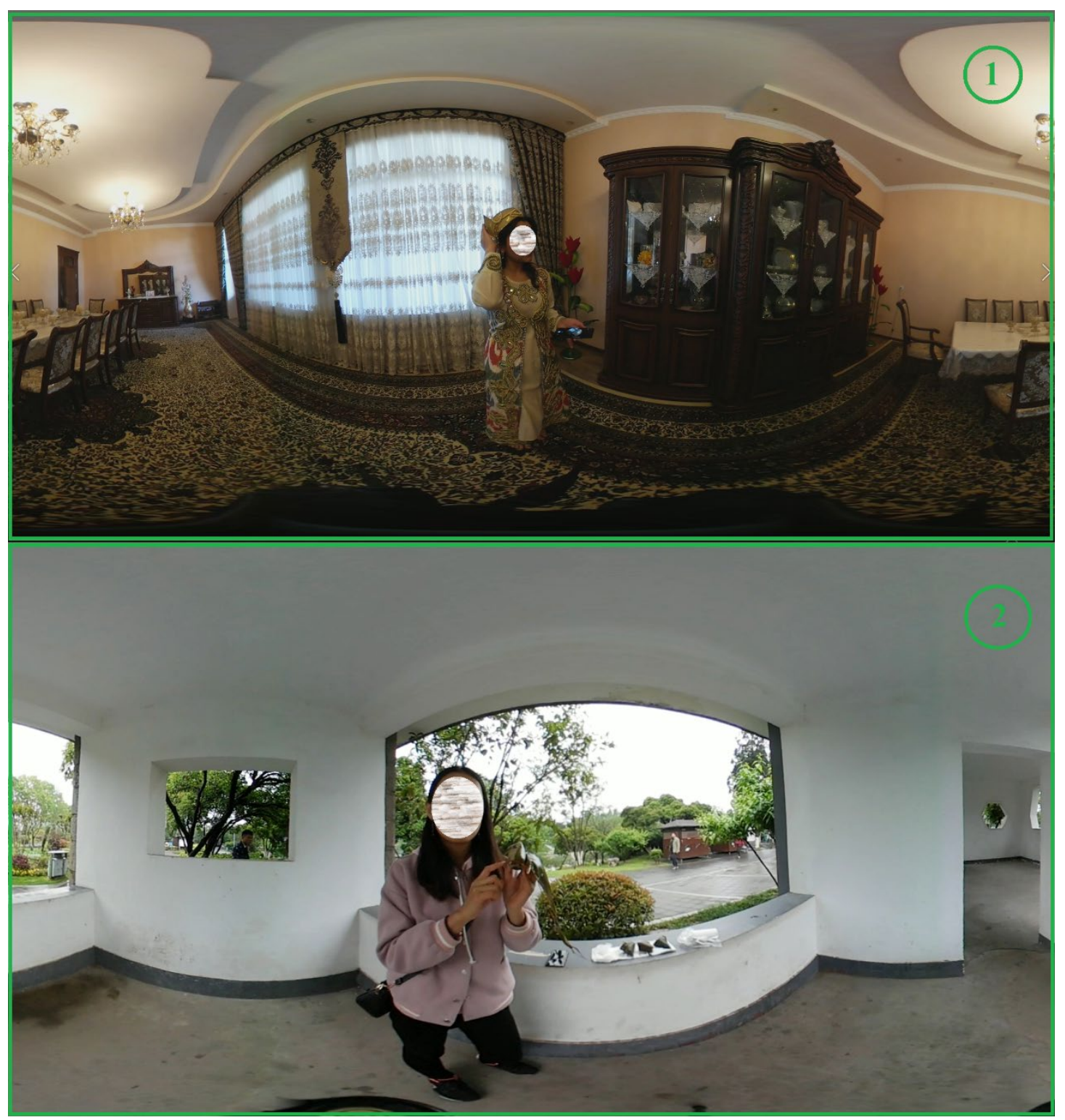

Figure 1. Screenshots from a 360-degree video. 


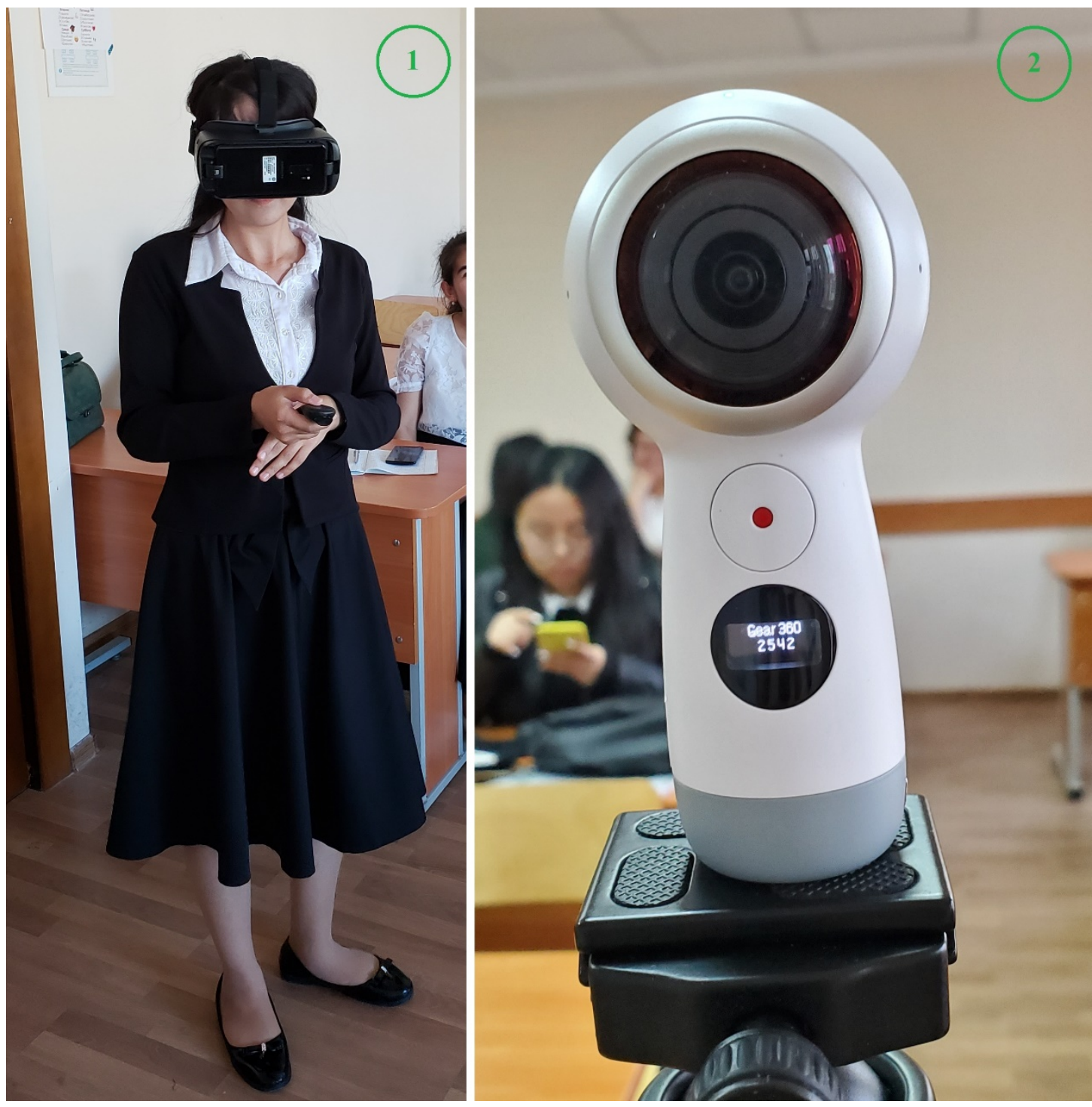

Figure 2. VR technology: (1) Samsung Gear VR, and (2) Samsung Gear 360.

\section{Research Procedure}

The learning activity was carried out and the data were collected both in China and Uzbekistan. We collected demographic information and assessed the IC of the participants before the learning activity (i.e., a pre-test) using a paper-based questionnaire. Then, the participants were informed about the learning activity. After that, the participants were taught how to use the VR technology and the online website, and then they practiced using them. Next, the participants carried out the learning activity. After the learning activity, we surveyed the participants' IC (i.e., a post-test) and perceptions of the VR technology using another paper-based questionnaire. In addition, the participants completed reflective reports, and we carried out one-on-one interviews with them. The researchers in this study were not teachers but were involved in the data collection and analysis process.

\section{Data Collection}

To answer the research questions, both quantitative and qualitative data were gathered. We collected 
data from participants' reflections and interviews to answer research question 1, participants' perceptions of VR technology to answer research question 2, and participants' perceived IC to answer research question 3. Descriptions of the components of the data are presented here:

- Reflective reports. The students wrote reflective reports in which they described their experiences related to intercultural learning supported by VR technology.

- One-on-one semi-structured interviews. Each interview lasted approximately 30 minutes, in which the students were asked open-ended questions:

1. What was your development of IC in terms of four dimensions, i.e., knowledge, attitude, skills, and awareness?

2. Please describe your experience with the use of VR technology.

3. What do you think about the usefulness of VR technology for intercultural learning?

- The expectation-confirmation questionnaire. This questionnaire (Bhattacherjee, 2001) was used to measure participant perceptions of VR technology. It included three dimensions, with a total of 12 items: continuance intention (3 items), satisfaction (4 items), and confirmation (5 items). We used a Likert scale and anchored the end points with completely disagree (1) and completely agree (7).

- The assessment of intercultural competence (AIC) questionnaire. This questionnaire (Fantini, 2009) included four dimensions and 39 items: knowledge (10 items), attitudes (11 items), skills (8 items), and awareness (10 items). These items were rated on a six-point Likert scale. We anchored the end points of the scale with no competence (0) and very high competence (5). The scope of IC was narrowed to student competence related to the topics covered in this study.

All data were anonymized to ensure confidentiality.

\section{Data Analysis}

Twenty-one valid answer sheets to the questionnaires were obtained from the 21 students. We analyzed the responses to the questionnaire following the general recommendations of Hsu and Beasley (2019). First, we checked all responses, and no evidence of response bias was found. Second, we checked for the internal consistency of each questionnaire using Cronbach's alpha. The values in each dimension ranged from 0.802 to 0.943 , which demonstrated satisfactory reliability. Third, we calculated the descriptive statistics for each dimension and analyzed the data to provide answers to the research questions. An independent sample $t$-test was used to compare the IC scores before and after the activity. SPSS statistical analysis software was employed to make the calculations.

All interviews were audio-recorded, transcribed, and translated from Chinese/ Uzbek into English. The interview transcripts and reflective reports from all students were used for the qualitative data analysis. We used a content analysis method in which the transcripts and reflections were read through, text 
segments in the data relevant to the research questions were highlighted and coded by two raters individually, and codes with similar meanings were aggregated. All codes were gathered into different categories to report the findings. Finally, raters compared and discussed the codes and categories to reach a consensus.

\section{Results and Discussion}

\section{Perceptions of the Intercultural Learning Activity}

Thirteen codes were derived, and three categories emerged from them (see Appendix A).

Authenticity of learning environment. This category included a real environment, a real partner, and visualization codes. The students indicated that they felt the environments and partners were real when they used VR technology. Compared with other VRs (e.g., Second Life), the one used in this study provided a real-world scene rather than an artificial, human-made environment. In addition, intercultural partners communicated with real people, not avatars. This finding is consistent with other studies. The participants in Liao and Lu (2018) who were visiting a campus through VR felt they were experiencing another real world while controlling a telepresence robot. In our study, the participant ID3 mentioned that, "[The technology] can create a real atmosphere for me, and the intercultural partners are also real. This three-dimensional perspective of her is pretty strong, and I could observe this person, the way she dresses, the way she behaves." In addition, the participants mentioned that the learning content was more vivid than content in textbooks or on the Internet because it could materialize and visualize abstract knowledge. For example, participant ID8 mentioned that, "When introducing traditional food, I can change my perspective as if I am in the scene, to see how the food is made, what ingredients are used, and I can capture its color and shape, which is very vivid."

In this study, VR technology enhanced the participants' sense of immersion and presence. As a result, the participants felt that the learning content and contexts were authentic. This is very important for intercultural learning because such advantages facilitate learning. This is something that previous studies were unable to show.

Authenticity of the foreign culture. Three codes, including authentic experience, presence, and immersion, were in this category. Authentic experience means that the VR learning content was authentic, i.e., created by a real person in his/her country, and the participants learned about the foreign culture using it. Because the participants perceived the learning environment as real, they had a sense of being in the real world, which is called place illusion or presence (Slater, 2009). Scholars have suggested that highly immersive VR experiences may lead users to feel as if their consciousness has been relocated to the virtual space (Slater, 2009). For example, participant ID3 mentioned, "When I studied my partner's culture, I felt like I was standing beside her." According to Liao and Lu (2018), authentic learning experiences are created by making learners feel that they are engaged in the activity as if they are physically present. The participants in our study said they gained real cultural knowledge and experience by participating in VR-supported learning activities. Similar findings have been reported in other related studies (Liao \& Lu, 2018). In addition to giving participants a sense of presence 
(Higuera-Trujillo, Maldonado, \& Llinares Millán, 2017), the VR technology created an immersive learning environment (Rupp et al., 2019; Walshe \& Driver, 2019). According to Higuera-Trujillo et al. (2017), higher levels of immersion elicit a greater sense of presence, which is understood as an unmediated perceptual illusion that can only be quantified by user experience (Rupp et al., 2019; Walshe \& Driver, 2019). In previous studies, participants with different cultural backgrounds exchanged cultural information with each other using technology to achieve intercultural learning. Although the cultural knowledge learned by the participants in these studies was authentic, or came from the authentic culture, the participants did not have a sense of presence in the specific culture, so they couldn't have an authentic experience, let alone a sense of immersion.

Learning category. This category included the following seven codes: enthusiasm, motivation, curiosity, attention, understanding, convenience, and interest. In term of enthusiasm, motivation, and interest, the participants said in the interviews that VR made their learning experience new and interesting (Hsu \& Beasley, 2019; Lee \& Markey, 2014; Shadiev et al., 2015), which greatly improved their enthusiasm related to intercultural learning (Shih, 2015). In addition, participants were very motivated to learn about other cultures in VR (Bueno-Alastuey \& Kleban, 2016; Lee \& Markey, 2014; Shadiev \& Huang, 2016; Shih, 2015). For example, participant ID9 said, "This way to learn interculturally has increased my enthusiasm, and I love to learn about their culture," and "I want to know more about their culture." Participant ID5 stated, "I can learn about their culture, and it is interesting and fun."

Curiosity was stimulated by the fact that participants could use their senses to explore and discover other cultures (Shih, 2015). For example, participant ID7 stated, "I am very interested in their buildings and surrounding environment, and as a result, I have a feeling that I want to visit this place, and there is a sense of curiosity."

VR technology has the potential to improve attention. The participants reported that when they were engaged in intercultural learning in VR, their attention was focused on the content. For example, participant ID7 stated, "I was totally focused on learning about their culture. I didn't know what was going on outside, and I wasn't disturbed by it."

As mentioned earlier, the learning environment created by the VR technology was real, so participants could understand the cultural information provided by their partners. For example, participant ID5 stated, "When I knew that she was introducing me to their traditional clothes, I could barely imagine what it looked like. When I watched the 360-degree video, I could fully understand what she said about traditional clothes."

The participants expressed that the learning activity supported by VR technology was easy and convenient because it enabled a long-distance intercultural immersion experience. For example, participant ID2 stated, "This way of intercultural learning is convenient. I don't need to spend a lot of time and money to go to another country."

Our findings are similar to those from earlier research (Bueno-Alastuey \& Kleban, 2016; Rupp et al., 2019; Shadiev \& Huang, 2016; Shadiev et al., 2015; Shadiev et al., 2019; Shadiev, Wu, Sun, \& Huang, 
2018; Vettehen et al., 2019; Walshe \& Driver, 2019). However, since we used VR technology based on Gear 360 and Gear VR, participants' sense of immersion and presence increased, and they perceived the learning content and contexts to be real. As mentioned earlier, learning content and contexts are important because they facilitate intercultural learning.

The above-mentioned advantages can be useful for learners, educators, and researchers when designing courses as well as during intercultural learning activities supported by VR technology. If learners, educators, and researchers know the advantages then they can make good use of these in future learning projects.

\section{Participants' Perceptions of VR Technology}

The mean values and standard deviations of the participants' perceptions of VR technology are presented in Appendix B. Participants had positive perceptions related to their intention to use VR technology continuously, degree of satisfaction, and confirmation of expectations. According to the results, the participants planned to continue to use VR technology (total $M=5.92 ; S D=0.989 ; 92 \%$ ). For example, $90.5 \%$ of participants were willing to use VR technology continuously rather than alternatives. Only three students were undecided. In the interviews, they said that the VR technology had greatly assisted their learning; however, because technology is developing very rapidly, they may choose to use alternatives if there are better ones.

Almost all participants were satisfied with their decision to use VR technology and with their usage experience (total $M=6.19 ; S D=0.828 ; 97 \%$ ). For example, participant ID10 said in the interviews that, "This technique gives me a full view of the learning content and context. When my partner was introducing a tradition, I could observe the environment around me as if I was really there. I am very satisfied with my learning experience.”

The participants had positive perceptions about their expectations being met (total $M=5.81 ; S D=1.000$; 90.5\%). Only two students either somewhat disagreed or were undecided regarding items 9, 10, and 11. In the interviews, they mentioned that their partners' 360-degree videos did not provide all the information they would have liked to have had, so they had to search for additional information on the Internet. In addition, their expectations regarding VR technology had been too high; i.e., they thought it would be like watching commercially made $5 \mathrm{D}$ movies.

Our results are consistent with those obtained in previous studies (Hsu \& Beasley, 2019; Lee \& Markey, 2014; Shadiev \& Huang, 2016; Shadiev et al., 2015; Shadiev et al., 2019; Shadiev et al., 2018). The students in related studies also had positive perceptions regarding their expectations being met.

\section{Participants' IC Development}

The results of the independent sample $t$-test (see Appendix C) showed that there was a significant difference between the IC pre- and post-test in four dimensions. The results suggest that the participants developed IC in all four dimensions. That is, the participants learned and mastered the cultural information they were exposed to in the activity, used skills to promote learning traditions and their own culture as well as that of their partners, and had a positive attitude and strong curiosity about the other culture. The results of the interviews and reflective reports confirmed these findings. 
Knowledge. The participants scored significantly higher on the post-test (total $M=3.77$; $S D=0.763$ ) as compared to the pre-test (total $M=0.70 ; S D=0.704$ ),$p<.005$. The result shows that there was a significant increase in participants' intercultural knowledge. This suggests that the intercultural activity affected the participants' knowledge of the foreign culture they were exposed to. In the interviews and reflective reports, the participants mentioned that they had no prior knowledge about the foreign cultures and traditions before participating in this activity, so they didn't know the essential norms and taboos of the foreign culture. In addition, the participants said they had been unable to contrast aspects of their own culture with those of the foreign culture prior to the activity, so they did not know how to describe the similarities and differences between them. The participants also mentioned that before participating in this activity, they only knew one technological tool to help learn about foreign culture, which was the Internet. Therefore, they did not know how to aid their learning, nor were they able to cite any strategies for learning about a foreign culture. The participants gained information about foreign cultures, values, and traditions by participating in the activity. All participants admitted that they had obtained cultural knowledge and had learned about their foreign peers, their cultures, and their traditions. In their reflective reports, they were able to recall what they had learned about the foreign culture and always compared the information they had learned with their own culture to find similarities and differences. They also attempted to cite strategies for their learning. Here is an extracted excerpt from a reflective report of student ID5:

I learned that they have a historical building called "memory square," which shows their respect for the soldiers who fought in WWII. In our country, we also use historic buildings or traditional festivals to show our respect for those who have passed away. Our cultures are similar in this respect. Also, in our country, people hold such ceremonies, too, but I was surprised by the respect their country had for the soldiers who fought in WWII. Compared with them, we also have differences. For example, we don't offer flowers, but we do pay the highest tribute to the deceased.

Attitude. The participants scored significantly higher on the post-test (total $M=4.232$; $S D=0.800$ ) as compared to the pre-test (total $M=1.39 ; S D=1.069$ ), $p<.005$. This result shows that there was a significant increase in participants' intercultural attitude. This suggests that the intercultural activity affected the participants' attitudes toward their foreign peers and the new culture they were exposed to.

In the interviews and reflective reports, the participants said they were not familiar with the values of the foreign culture they were learning about, so they did not know how to interact or communicate with their peers from that culture. In addition, the participants had never communicated with foreigners and had no experience with intercultural learning. Therefore, they did not have a positive attitude towards intercultural communication before participating in this activity. For example, participant ID8 initially said she felt nervous and uneasy about communicating with strangers, and also had no confidence that she could obtain or share cultural information properly in English in such a way so as to not offend her partners. However, after the learning activity, she had no such issues. All participants mentioned that because of the learning activity, they were interested in different aspects of the foreign culture and in introducing their own culture to others. In addition, they had the opportunity to try to understand and 
respect cultural differences and to try to interpret them. Here is another extract from the reflective report of student ID2:

I am also interested in the national characteristics of their cultures and would like to continue to learn about those cultures that are special/different from other cultures. I also want to introduce to them to our unique culture to give them a sense of our history, such as the hot pot in Chengdu, Sichuan embroidery, and the thatched cottage in Du Fu.

Skills. According to the results, the participants scored significantly higher on the post-test (total $M=3.98 ; S D=0.746$ ) as compared to the pre-test (total $M=0.81 ; S D=0.758$ ), $p<.005$. The result shows that there was a significant increase in participants' intercultural skills. This suggests that the intercultural activity affected the participants' skills related to the foreign culture they were exposed to.

In the interviews and reflective reports, the participants said that due to lack of intercultural communication, knowledge about their partners' culture, and experience with intercultural learning, they had no idea how to interact with their partners or to understand the differences between their cultures. Therefore, it was difficult for them to adjust their behaviour or dress appropriately to avoid offending their partners. They also indicated that they did not have any appropriate strategies for learning about a foreign culture and adapting to it in order to reduce cultural stress. All participants mentioned that these issues were resolved thanks to the activity. In addition, the participants were able to compare and contrast the foreign culture with their own. Here is one extract from reflective report of student ID4:

What impressed me most is that after the bride and groom get married, the couple go to the groom's home to sit down for a while. The groom's parents and relatives give gifts to the bride; the parents give jewelry, and the relatives give practical objects that are often used in married life. In addition, one student mentioned a historical building that contains the tomb of Suzukotas, where people read the Koran. In China, for example, in the Zhongshan mausoleum, tourists will visit Sun Yat-Sen's mausoleum, but they will not read and recite sutras there, which is quite different. This difference has to do with the country's economy, historical development, and political system. I used the strategies of knowledge transfer and empathy. By recalling the information introduced by the teacher in the history class, I analyzed how China developed to the present step by step. In this way, I looked at the culture of Uzbekistan and guessed the reasons for the differences.

Awareness. The participants scored significantly higher on the post-test (total $M=3.80$; $S D=0.690$ ) as compared to the pre-test (total $M=0.70 ; S D=0.672$ ),$p<.005$. The result shows that there was a significant increase in participants' intercultural awareness. This suggests that the intercultural activity affected the participants' awareness about the foreign culture they were exposed to.

In the interviews and reflective reports, participants mentioned that they had limited intercultural awareness before the activity. After participating in the activity, their intercultural awareness had developed. For example, they were able to identify the diversity in the foreign culture. Furthermore, they recognized the danger of interpreting individual behaviour as representative of a whole culture, 
and they knew how their own values were reflected in the intercultural learning process. In addition, they were able to contrast the foreign culture with their own and find similarities and differences which led to the development of cultural awareness. This is illustrated in this extract from the reflective report of student ID7:

I was most impressed by a square with a monument containing the names of soldiers who fought in the Second World War and a statue, all of which are meant to honour them and remind us to remember the history of that war. In our country, there are also monuments with historical and educational significance. We also hold activities on special days to remind people not to forget national pride and to remember historical events.

These results, related to IC development (i.e., knowledge, attitude, skills, and awareness), were confirmed by the instructors and researchers in this study. We therefore can conclude that intercultural learning supported by VR technology helped develop the participants' IC in all four dimensions. In intercultural education, the cultivation of IC has been the concern of many researchers. This finding is consistent with those of previous studies (Bueno-Alastuey \& Kleban, 2016; Hsu \& Beasley, 2019).

\section{Conclusion}

The results of this study showed thirteen advantages of intercultural learning supported by VR. Many of these advantages have been mentioned in related studies. However, three have not and therefore are new to this field of research: presence, authentic cultural experience, and immersion. The participants positively perceived the VR technology as supporting intercultural learning, i.e., they intended to use the technology in the future, were satisfied with their learning experiences, and felt that the technology met their expectations. In addition, the intercultural learning supported by VR technology was helpful in facilitating IC development.

The results of this study may be useful for educators and researchers in the field of open and distributed learning because this study spans geographic and cultural boundaries using educational technology, where resources created by students are in open access and therefore easily accessible.

Based on these results, we suggest that researchers and educators use VR technology to support longdistance intercultural learning. Apart from the ten previously identified advantages of intercultural learning, VR technology can provide participants with a sense of presence, immersion, and authenticity. As technology develops, we suggest that researchers and educators use VR tools to support both asynchronous and synchronous communication in long-distance intercultural learning. Scholars have warned that learners may experience fatigue/sickness in VR (Rupp et al., 2019). Therefore, we suggest that, to avoid discomfort, videos should not be too long. Finally, videos should have interesting, easy topics so that the students who record and watch them will be motivated to learn. 


\section{Promoting Intercultural Competence in a Learning Activity Supported by Virtual Reality Technology \\ Shadiev, Xueying, and Huang \\ References}

Avgousti, M.I. (2018). Intercultural communicative competence and online exchanges: A systematic review. Computer Assisted Language Learning, 31(8), 819-853. doi: $\underline{10.1080 / 09588221.2018 .1455713}$

Byram, M. (1997). Teaching and assessing intercultural communicative competence. Clevedon: Multilingual Matters.

Bhattacherjee, A. (2001). Understanding information systems continuance: An expectationconfirmation model. MIS Quarterly, 25(3), 351-370. doi: 10.2307/3250921

Bueno-Alastuey, M.C., \& Kleban, M. (2016). Matching linguistic and pedagogical objectives in a telecollaboration project: A case study. Computer Assisted Language Learning, 29(1), 148166. doi: $10.1080 / 09588221.2014 .904360$

Çiftçi, E.Y. (2016). A review of research on intercultural learning through computer-based digital technologies. Journal of Educational Technology \& Society, 19(2), 313-327. Retrieved from https://www.jstor.org/stable/pdf/jeductechsoci.19.2.313.pdf

Deardorff, D.K. (2006). Identification and assessment of intercultural competence as a student outcome of internationalization. Journal of Studies in International Education, 10(3), 241266. doi: $\underline{10.1177 / 1028315306287002}$

Fantini, A. (2009). Assessing intercultural competence. Issues and tools. In D.K. Deardorff (Ed.), The SAGE Handbook of Intercultural Competence (pp. 456-476). Thousand Oaks: Sage.

Higuera-Trujillo, J.L., Maldonado, J.L., \& Llinares Millán, C. (2017). Psychological and physiological human responses to simulated and real environments: A comparison between Photographs, $360^{\circ}$ Panoramas, and Virtual Reality. Applied Ergonomics, 65, 398-409. doi: 10.1016/j.apergo.2017.05.006

Hsu, S.Y., \& Beasley, R. (2019). The effects of international email and Skype interactions on computer-mediated communication perceptions and attitudes and intercultural competence in Taiwanese students. Australasian Journal of Educational Technology, 35(1), 149-162. doi: 10.14742/ajet.4209

Lee, L., \& Markey, A. (2014). A study of learners' perceptions of online intercultural exchange through Web 2.o technologies. ReCALL, 26(3), 281-297. doi: 10.1017/So958344014000111

Liao, J., \& Lu, X. (2018). Exploring the affordances of telepresence robots in foreign language learning. Language Learning \& Technology, 22(3), 20-32. doi: 10125/44652

Rupp, M.A., Odette, K.L., Kozachuk, J., Michaelis, J.R., Smither, J.A., \& McConnell, D.S. (2019). Investigating learning outcomes and subjective experiences in 360-degree videos. Computers \& Education, 128, 256-268. doi: 10.1016/j.compedu.2018.09.015 
Shadiev, R. \& Huang, Y.M. (2016). Facilitating cross-cultural understanding with learning activities supported by speech-to-text recognition and computer-aided translation. Computers \& Education, 98, 130-141. doi: 10.1016/j.compedu.2016.03.013

Shadiev, R., Hwang, W.Y., \& Huang, Y.M. (2015). A pilot study: Facilitating cross-cultural understanding with project-based collaborative learning in an online environment. Australasian Journal of Educational Technology, 31(2), 123-139. doi: 10.14742/ajet.1607

Shadiev, R. \& Sintawati, W. (2020). A review of research on intercultural learning supported by technology. Educational Research Review, 31, 1-12. doi: 10.1016/j.edurev.2020.100338

Shadiev, R., Sun, A. \& Huang, Y.M. (2019). A study of the facilitation of cross-cultural understanding and intercultural sensitivity using speech-enabled language translation technology. British Journal of Educational Technology, 5O(3), 1415-1433. doi: 10.1111/bjet.12648

Shadiev, R., Wu, T.T., Sun, A., \& Huang, Y.M. (2018). Applications of speech-to-text recognition and computer-aided translation for enhancing cross-cultural learning: issues and their solutions. Educational Technology Research and Development, 66(1), 191-214. doi: 10.1007/s11423017-9556-8

Shih, Y.C. (2015). A virtual walk through London: Culture learning through a cultural immersion experience. Computer Assisted Language Learning, 28(5), 407-428. doi: $\underline{10.1080 / 09588221.2013 .851703}$

Slater, M. (2009). Place illusion and plausibility can lead to realistic behaviour in immersive virtual environments. Philosophical Transactions of the Royal Society of London B Biological Sciences, 364(1535), 3549-3557. doi: 10.1098/rstb.2009.0138

Vettehen, P.H., Wiltink, D., Huiskamp, M., Schaap, G., \& Ketelaar, P. (2019). Taking the full view: How viewers respond to 360-degree video news. Computers in Human Behavior, 91, 24-32. doi:

Walshe, N., \& Driver, P. (2019). Developing reflective trainee teacher practice with 360-degree video. Teaching and Teacher Education, 78, 97-105. doi: 10.1016/j.tate.2018.11.009

Yang, R. (2018). The use of questions in a synchronous intercultural online exchange project. ReCALL, 3O(1), 112-130. doi: 10.1017/So958344017000210

Athabasca University

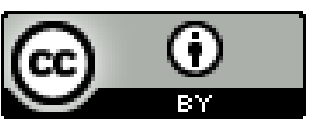


Promoting Intercultural Competence in a Learning Activity Supported by Virtual Reality Technology Shadiev, Xueying, and Huang 